Check for updates

Cite this: RSC Adv., 2018, 8, 32684

Received 31st July 2018

Accepted 14th September 2018

DOI: $10.1039 / c 8 \mathrm{ra06460a}$

rsc.li/rsc-advances

\section{Ethylenediamine mediated luminescence enhancement of pollutant derivatized carbon quantum dots for intracellular trinitrotoluene detection: soot to shine $\uparrow$}

\author{
S. Devi, ${ }^{a}$ Raju K. Gupta, ${ }^{\text {D }}{ }^{\text {b }}$ A. K. Paul, ${ }^{c}$ Vinay Kumar, ${ }^{d}$ Abhay Sachdev, ${ }^{a}$ P. Gopinath ${ }^{d}{ }^{d}$ \\ and S. Tyagi (D) *a
}

\begin{abstract}
Vehicle-generated toxic pollutants are composed of gaseous smoke and particulate byproducts accumulated as a black substance at its exhaust. This particulate matter (soot) is utilized for the green synthesis of highly stable, non-toxic, environment friendly, carbon quantum dots (CQD). The CQDs are synthesized via the simple hydrothermal route in the absence (C1) and presence (C2) of oxidants. The as-synthesized CQDs are amine functionalized using ethylenediamine. The amine functionalized CQDs (C1N and C2N) are explored for trinitrotoluene detection. From transmission electron microscopy, the average size of $\mathrm{C} 1$ and C2 was found to be about $4.2 \mathrm{~nm}$ and $5.6 \mathrm{~nm}$ respectively. The incorporation of amine groups lead to an increase in quantum yields from $5.63 \%$ to $12.7 \%$ for $\mathrm{C} 1$ and from $3.25 \%$ to $8.48 \%$ for $C 2$ QDs. A limit of detection (LOD) of $13 \mathrm{ppb}$ was displayed by C1N while the LODs of $11 \mathrm{ppb}$ and $4.97 \mathrm{ppb}$ were delivered by $\mathrm{C} 2 \mathrm{~N}$ at $\lambda_{\text {ex }} 370 \mathrm{~nm}$ and $\lambda_{\text {ex }} 420 \mathrm{~nm}$ respectively. The Stern-Volmer constant for $\mathrm{C} 1 \mathrm{~N}$ is $2.02 \times 10^{6} \mathrm{M}^{-1}$ while for $\mathrm{C} 2 \mathrm{~N}$ at $\lambda_{\text {ex }} 370 \mathrm{~nm}$ and $\lambda_{\text {ex }} 420 \mathrm{~nm}$ is $0.38 \times 10^{6} \mathrm{M}^{-1}$ and $0.48 \times 10^{6} \mathrm{M}^{-1}$ respectively. Furthermore, C1N presents high selectivity for TNT compared to C2N. Owing to their higher luminescence, C1N particles are successfully demonstrated for their applicability in intracellular TNT detection.
\end{abstract}

\section{Introduction}

Transportation is a major source of pollution in the world due to a large number of available vehicles. Vehicle-generated pollutants, such as carbon monoxide, hydrogen, nitrogen oxide, vehicle soot or particulate matter, ammonia and sulfur dioxide, impose many adverse effects on living such as health and the environment. ${ }^{1}$ The release of burnt fuel byproducts and soot into the atmosphere is the main cause for transportation mediated environment pollution. A black substance can be noticed looking at the exhaust of a car. With time, a lot of this accumulates and the soot is spread in the air and on the ground as the car moves, which is very harmful to people's health as well as the environment. ${ }^{1}$ The situation is much worse when the matter is fine because it can easily be spread by moving air. This results in global warming, poor air quality, lack of international reputation, various health issues, decreased tourism, smog, and

${ }^{a}$ Analytical Techniques Division, CSIR-CSIO, Chandigarh 160030, India. E-mail: matsachin@gmail.com; sachintyagi@csio.res.in; Fax: + 91-172-2657267; Tel: +91172-2642545 (O)

${ }^{b}$ Indian Institute of Technology, Kanpur, Uttar Pradesh, India

${ }^{c}$ DeshBhagat University, Fatehgarh Sahib, Punjab, India

${ }^{d}$ Indian Institute of Technology Roorkee, Roorkee, Uttarakhand, India

$\uparrow$ Electronic supplementary information (ESI) available. See DOI: 10.1039/c8ra06460a acidic rain. The gaseous products are difficult to handle directly while the vehicle soot can be hindered for their direct entrance in the environment by reusing the soot. Carbon quantum dots (CQDs) have come into view as a recently developed and very potential fluorescent nanomaterial due to its outstanding optical properties, fantastic biocompatibility and accessible surface functional groups. ${ }^{2}$ CQDs deliver large application potential in a variety of areas. CQDs, can further be explored for various applications in different fields especially in chemosensing $^{3}$ and biosensing applications, ${ }^{4}$ including photocatalysis, ${ }^{5}$ photovoltaic devices, ${ }^{6}$ optoelectronics, ${ }^{7}$ bioimaging, ${ }^{8,9}$ biolabeling, ${ }^{10}$ drug delivery, ${ }^{11}$ metal ion and explosive sensing ${ }^{\mathbf{1 2}}$ etc.

Presently, the researchers prefer the application of various natural bio-precursors over chemical modification and template-based synthesis for fabrication of carbon nanostructures via greener route. Several natural biomass precursors such as soy milk, ${ }^{13}$ sugarcane juice, ${ }^{14}$ coffee, ${ }^{15}$ egg yolk, ${ }^{16}$ and dextrin, ${ }^{17}$ and so on, have been reported for the CQDs synthesis. The resultant CQDs exhibited a high PL quantum yield (QY) and good water-solubility. Here, we report the synthesis of environment friendly, non-toxic and luminescent carbon quantum dots (CQDs) using the bike soot pollutant. This can be a possible approach in utilization of pollutant to the productive material, CQDs. 
Nitroaromatic compounds cover a large fraction of hazardous explosive materials and prove to be very lifethreatening upon long exposure. Trinitrotoluene (TNT) is one of the heavily used nitroaromatic explosives in various fields like mining, terrorist activities, military and defense area etc. which compels for its highly sensitive and selective detection. Different types of nanomaterials like dye-loaded porous nanomaterials, ${ }^{18}$ gold nanoparticles, ${ }^{19}$ and heavy metal $\mathrm{QDs}^{\mathbf{2 0}}$ have been explored for the optical detection of TNT. But their shortcomings like less stability, cell toxicity, scarce functionality, high size polydispersity and decreased hydrophilicity limits their application.

While, CQDs deliver plenty of alluring properties like intense fluorescence, high quantum yield (QY), large functionality, nontoxic nature, hydrophilicity, excellent biocompatibility, high photostability and tunable photoluminescence (PL) which can present their potential candidature for TNT detection and other advanced potential applications.

Previous reports on $p$-nitrophenol (NP), a nitroaromatic compound, explored different CQDs based probes like $\beta$-cyclodextrin functionalized $\mathrm{CQDS}^{21}$ and phenylboronic acid functionalized CQDs (PBA-CQD) ${ }^{22}$ to detect NP forming nonfluorescent conjugates. Similar phenomenon of fluorescence quenching can be utilized for TNT detection by changing the functionalization ligand to amines on CQDs surface. Because for the phenolic nitroaromatic compounds like trinitrophenol (TNP) and NP, a different complex other than meisenheimer complex is formed with amine group which is yellow in colour. As shown by Wanko et al. for nitrophenolates, this complex is the result of the acid-base reaction between the amine group and the phenolic group to form phenolates. ${ }^{23,24}$ Therefore, amine ligand can deliver higher selectivity over different nitroaromatic TNT analogue compounds. So, amine capped CQDS can also be approached to selectively detect trinitrotoluene.

Therefore, in present research work carbon quantum dots were synthesized by using vehicle pollutant soot as precursor. The mechanism for the formation of carbon dots involves the carbonization of its constituents such as carbon black, organic aerosol and organic carbon etc. Further, synthesis route was optimized for the effect of absence (C1) and presence of oxidant nitric acid (C2). C1 and C2 were successfully amine functionalized with ethylenediamine (EDA) and explored for sensing of TNT. As lung cells are highly prone to explosive blast damage due to hemorrhage which is the primary blast effect on lungs that occurs due to overpressure and overpressure duration. ${ }^{25}$ So, clinging to this fact, TNT is also detected in liver cells (normal epithelial lung cell line, L-132) to advance the usability of this nanoprobe for intracellular TNT detection.

The "Turn Off" principle behind the TNT detection using these amine capped CQDs, C1N (derived from C1) and C2N (derived from C2) is shown in Fig. 1.

\section{Experimental}

\subsection{Materials and methods}

The pollutant soot was collected form Hero Splendor plus 2009 bike's exhaust pipe and used as precursor for CQDs synthesis.

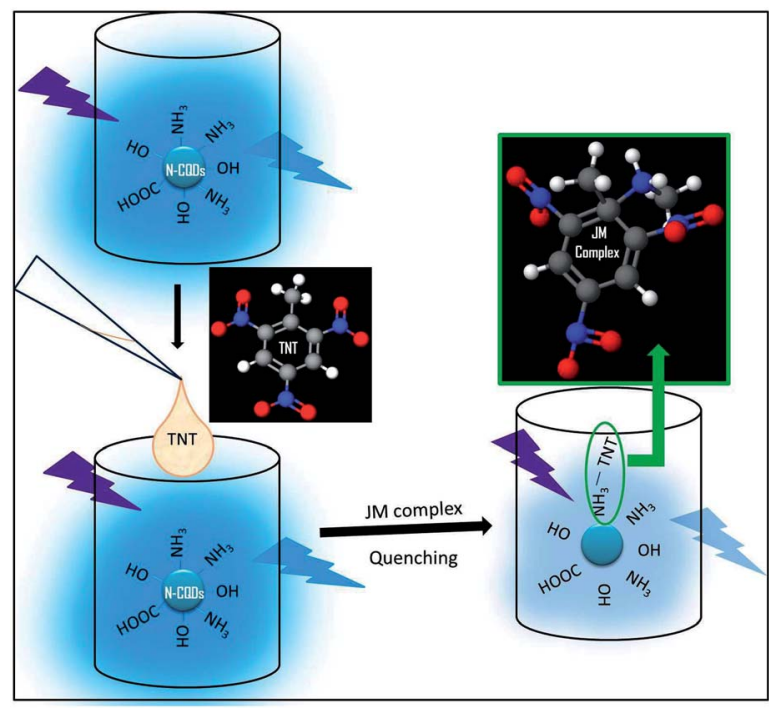

Fig. 1 Schematic illustration of the principle for TNT detection using N-CQDs

Quinine sulfate (QS, 99.5\%, AR) was supplied by $\mathrm{CDH}$, India. 2,4,6-trinitrotoluene (TNT), dinitrotoluene (DNT) and 2,4-dinitrotoluic acid (TA) were purchased from Sigma Chemical Co. (USA). $\mathrm{HNO}_{3}$ and sulphuric acid $\left(\mathrm{H}_{2} \mathrm{SO}_{4}\right)$ were supplied by Merck. Dialysis membrane-70 was bought from himedia. Disodium ethylenediaminetetraacetate dehydrate ( $\mathrm{Na}_{2}$ EDTA), Sodium bicarbonate $\left(\mathrm{NaHCO}_{3}\right)$, nitrobenzene (NB) was purchased from Sigma-Aldrich. Deionized water $(18 \mathrm{~m} \Omega)$ was used throughout the study. All the chemicals were of analytical grade and used without further purification.

\subsection{Synthesis of CQDs (C1 and C2)}

The hydrothermal synthesis of CQDs involves: (i) collection, grinding and sieving of bike soot (ii) carbonization of soot powder in respective solvents and (iii) purification of the product. The bike soot was collected in a glass Petri dish and grinded with pestle mortar to break the clumps. After sieving, the $0.02 \mathrm{~g}$ fine soot powder was mixed in $10 \mathrm{~mL}$ of DI water for the synthesis of $\mathrm{C} 1$. This solution was subjected to heat treatment in a $25 \mathrm{~mL}$ Teflon-lined autoclave at $140^{\circ}$ for $10 \mathrm{~h} .40 \mathrm{~mL}$ DI water was added into the dark brown colored product and centrifuged at $10000 \mathrm{rpm}$ for $15 \mathrm{~min} .10 \mathrm{~mL} \mathrm{C1}$ solution was dialyzed in $8 \mathrm{~cm}$ long activated dialysis membrane for $24 \mathrm{~h}$ against DI water. The deionized water was added in dialysate up to the final volume of $40 \mathrm{~mL}$ for further use.

C2 was synthesized using same procedure except the soot powder was mixed in $20 \mathrm{~mL} \mathrm{HNO}_{3}(6.4 \mathrm{M})$ solution and heat treated at $180^{\circ}$ for $8 \mathrm{~h}$ in Teflon-lined autoclave. The oxidative acid presence might affect the procedure in three expected manners: firstly, the breaking down the aggregates into nanosized carbon particles, secondly, for solubilization of carbon nanoparticles, and thirdly, influence the emission characteristics. The driving force for the synthesis of spherical CQDs from soot material can be discussed as the strong oxidizing acids used in synthesis of CQD, amplify the carbonization of small organic molecules of soot to carbonaceous materials. The 
oxidative acid presence might affect the procedure in three expected manners: firstly, the breaking down the aggregates into nano-sized spherical carbon particles, secondly, for solubilisation of carbon nanoparticles, and thirdly, influence the emission characteristics. ${ }^{26}$ Moreover, aggregation of CQD was avoided by controlled pyrolysis in Teflon lined autoclave during hydrothermal synthesis. ${ }^{27}$

\subsection{Amine capping of CQDs (C1N and C2N)}

C1 and C2 were capped with EDA to subject the amine group on their surfaces. The EDA concentration required for complete surface capping was optimized. $2 \mathrm{~mL}$ each of the $\mathrm{C} 1$ and $\mathrm{C} 2$ solutions were taken as reference. The EDA was added in C1 solution having the $\mathrm{C} 1: \mathrm{EDA}(\mathrm{v} / \mathrm{v})$ ratio of $1: 0.005,1: 0.01$, $1: 0.025,1: 0.05,1: 0.1,1: 0.2,1: 0.3,1: 0.4,1: 0.5$ and $1: 1$ $(0.075 \mu \mathrm{M}$ to $15 \mu \mathrm{M})$. Similarly, the EDA was added in C2 solution having the $\mathrm{C} 2$ : EDA $(\mathrm{v} / \mathrm{v})$ ratio of $1: 0.005,1: 0.01,1: 0.025$, $1: 0.25,1: 0.5$ and $1: 1(0.075 \mu \mathrm{M}$ to $15 \mu \mathrm{M})$. These solutions were checked for their PL emission intensity. The as-synthesized CQDs (C1, C2) and amine-capped CQDs (C1N, C2N) were characterized and compared using various analytical techniques. The schematic illustration of the synthesis and capping of C1 and C2 is shown in Fig. 2. The effects of dialysis and amine functionalization on the emission intensities of C1 and C2 are shown in Fig. S1 $\uparrow$ exhibiting the enhancement in their blue-colored emissions under the UV-illumination (365 $\mathrm{nm})$.

Here, the amine-terminated compound (EDA) acts as surface passivating agent for CQDs. The surface passivation is required for the enhanced photoluminescence (PL) of the CQDs. ${ }^{27}$

\subsection{Quantum yield (QY) calculations}

The standard dye used to measure the QY of the synthesized CQDs was quinine sulfate (QS) dissolved in $0.1 \mathrm{M} \mathrm{H}_{2} \mathrm{SO}_{4}$. The known QY of QS is 0.54 at $\lambda_{\mathrm{ex}} 330 \mathrm{~nm}$. The UV-vis absorption and PL emission spectra of QDs (C1, C2, C1N and C2N) and reference QS were measured separately. The QY values were calculated according to the equation as follow:

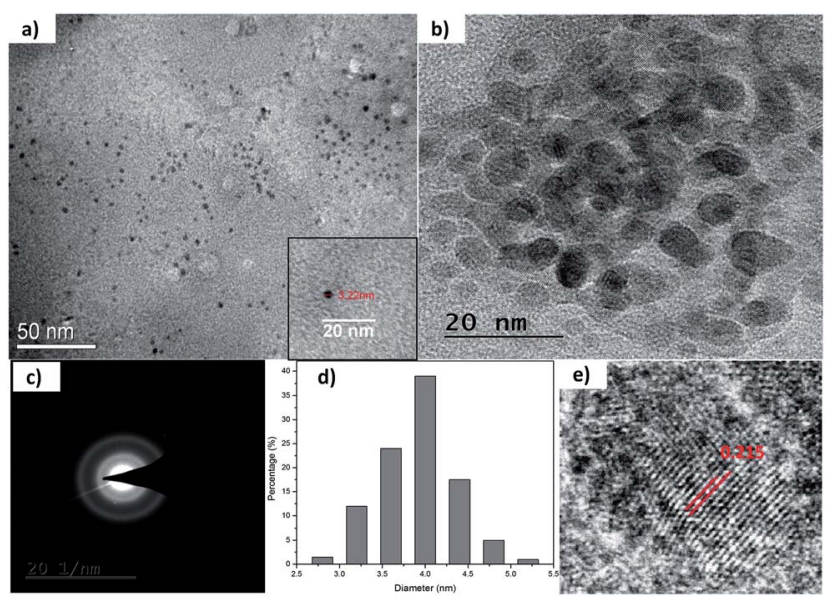

Fig. 2 (a) and (b) TEM micrographs of as-synthesized C1 at different scales; (c) SAED pattern; (d) size distribution; and (e) lattice fringe analysis of as-synthesized $\mathrm{C} 1$.

$$
\Phi_{\mathrm{x}}=\Phi_{\mathrm{ST}}\left(\frac{\operatorname{Grad}_{\mathrm{x}}}{\operatorname{Grad}_{\mathrm{ST}}}\right)\left(\frac{\eta_{\mathrm{x}}^{2}}{\eta_{\mathrm{ST}}^{2}}\right)
$$

In here ' $\mathrm{x}$ ', 'ST', ' $\Phi$ ' and 'Grad' stand for sample, standard, fluorescence quantum yield and the gradient from the plot of integrated emission intensity $v s$. absorbance respectively. The $\eta$ represents the refractive index of solvents which is 1.33 for both the solvents $0.1 \mathrm{M} \mathrm{H}_{2} \mathrm{SO}_{4}$ and water.

\subsection{TNT sensing study}

Standard stock solutions $\left(10^{4} \mathrm{ppm}\right)$ of TNT and various other nitroaromatic analogues compounds were prepared in acetonitrile. The TNT sensing study was performed using PL spectroscopy at different TNT concentrations as prepared from stock solution $(220 \mu \mathrm{M}$ to $44 \mathrm{nM}$ in $\mathrm{C} 1 \mathrm{~N}$ solution and $0.308 \mu \mathrm{M}$ to $44 \mathrm{nM}$ in C2N solution). $3 \mathrm{~mL}$ of $\mathrm{C} 1 \mathrm{~N}$ and $\mathrm{C} 2 \mathrm{~N}$ solutions were used respectively for TNT detection $(n=3)$. For selectivity study, various other analogue nitroaromatic compounds (NB, DNT and 2-TA) were also studied using the PL spectroscopy.

\subsection{Analysis of real samples}

The tap water was vacuum filtered using a $0.22 \mu \mathrm{m}$ membrane for the removal of suspended particles. Then the samples were prepared by adding the known concentrations of TNT stock solution in filtered tap water. These TNT-spiked water samples were added in $\mathrm{C} 1 \mathrm{~N}$ and $\mathrm{C} 2 \mathrm{~N}$ solutions in $1: 29 \mathrm{v} / \mathrm{v}$ ratio to make a final TNT concentration of $0.1,1$ and $10 \mathrm{ppm}$. Finally, these samples were characterized for their PL emission properties. The fluorescence intensity of the samples was found having good recoveries.

\subsection{Cell culture}

The normal epithelial lung cell line, L-132, was obtained from National Centre for Cell Sciences (NCCS) Pune, India. These cells were cultured in Dulbecco's modified Eagle's medium (DMEM, Himedia) complemented with $10 \% \mathrm{v} / \mathrm{v}$ fetal bovine serum (FBS, Gibco Life Technologies) and 1\% penicillinstreptomycin solution (Sigma-Aldrich, USA). Cells were maintained in a humidified incubator ( $5 \% \mathrm{CO} 2 / 95 \%$ air atmosphere) at $37{ }^{\circ} \mathrm{C}$.

\subsection{MTT assay}

The cell viability of L-132 cells $\mathrm{C} 1 \mathrm{~N}$ at different concentrations

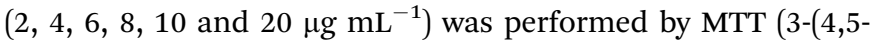
dimethylthiazol-2-yl)-2,5-diphenyltetrazolium bromide) assay on normal lung epithelial cell lines L-132. About 5000 cells were seeded on 96 well-plates and were then incubated at $37^{\circ} \mathrm{C}$ and 5\% CO2 for 12 hours. After 12 hours incubation, the different concentrations of $\mathrm{C} 1 \mathrm{~N}$ were added in each well and the cells were incubated at $37{ }^{\circ} \mathrm{C}$ and $5 \% \mathrm{CO} 2$ for 48 hours. All the samples were evaluated in triplicates to avoid any inconsistency in result interpretation. After the completion of incubation period, the spent media was removed and $100 \mu \mathrm{L}$ fresh media supplemented with $10 \mu \mathrm{L}$ MTT reagent $\left(5 \mathrm{mg} \mathrm{mL}^{-1}\right)$ was added to each well. The treated cells were again transferred to the 
incubator for another 4 hours at $37^{\circ} \mathrm{C}$ and $5 \% \mathrm{CO} 2$. At the end of the incubation period, the spent media was aspirated from each well and the formazan crystals formed by the cells was dissolved by adding $100 \mu \mathrm{L}$ DMSO to each well. Further the concentration of formazan crystals formed in each well was estimated by recording absorbance at $570 \mathrm{~nm}$ and background absorbance at $690 \mathrm{~nm}$ for the respective well in multimode plate reader (Biotek Cytation 3). The acquired absorbance values are converted to percentage of viable cells using the formula:

$$
\text { Cell viability }(\%)=\frac{\left(A_{570}-A_{690}\right) \text { treated cells }}{\left(A_{570}-A_{690}\right) \text { control cells }} \times 100
$$

\subsection{Intracellular bioimaging in presence of TNT}

For imaging experiments, L-132 cells were pre-treated with TNT $(4 \mathrm{ppm})$ for $12 \mathrm{~h}$. These TNT treated cells were further incubated with $20 \mu \mathrm{g} \mathrm{mL} \mathrm{m}^{-1}$ of $\mathrm{C} 1 \mathrm{~N}$ for another $4 \mathrm{~h}$, as the cells were observed having good viability at this concentration. Subsequently, the cells were washed with sterile phosphate buffer saline (PBS) in order to remove excess salt. Images were then captured using DAPI and GFP filters of fluorescence microscope (EVOS FL Colour, AMEFC 4300) for capturing the blue and green emission of CQDs.

\section{Results \& discussion}

\subsection{Characterization of as-synthesized C1 and C2}

The morphological characterization of $\mathrm{C} 1$ and $\mathrm{C} 2$ was performed using TEM. In Fig. $2 \mathrm{a}$ and $\mathrm{b}$, it can be observed that assynthesized C1 are having spherical shape, monodisperse nature and an average diameter of $4.2 \mathrm{~nm}$. The size distribution of these QDs can be seen in Fig. 2d. The as-synthesized C1 are amorphous in nature as revealed from selected area electron diffraction analysis (SAED) (Fig. 2c). The lattice fringes with inter-fringes distance of $0.215 \mathrm{~nm}$ can be assigned to the (100) diffraction planes of graphitic carbon (Fig. $2 \mathrm{e}$ ).$^{28}$ It attributes the presence of nanocrystalline cores of $\mathrm{sp}^{2}$ graphitic carbons which are in agreement with previous reports. ${ }^{28}$

The size and morphology of as-synthesized $\mathrm{C} 2$ can be viewed in Fig. 3. The TEM images of $\mathrm{C} 2$ at different scales are shown in Fig. 3a and b. It was observed that as-synthesized $\mathrm{C} 2$ are having spherical shape but are less monodisperse in nature in comparison to C1 (inset of Fig. 3a). The average diameter of C2

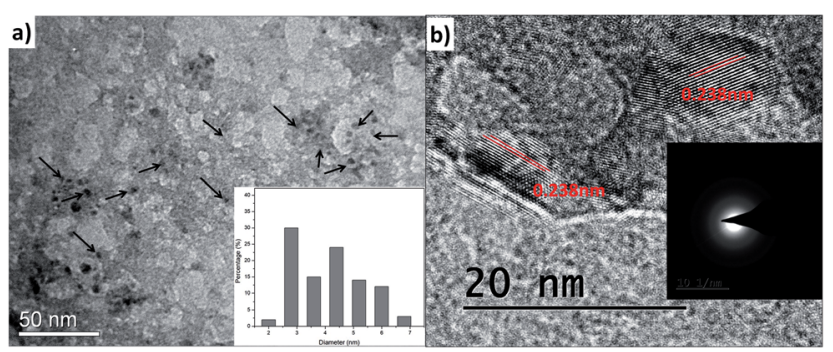

Fig. 3 (a) and (b) TEM micrographs of as-synthesized C2 at different scales with lattice fringe analysis; inset of (a) and (b) are size distribution and SAED pattern respectively. was $5.6 \mathrm{~nm}$. From SAED pattern (inset of Fig. 3b), it was noted that $\mathrm{C} 2$ are also amorphous in nature and have lattice fringes with inter-fringes distance of $0.23 \mathrm{~nm}$ (Fig. 3b) which again can be assigned to the (100) diffraction planes of graphitic carbon..$^{28}$ It proves the presence of nanocrystalline cores of $\mathrm{sp}^{2}$ graphitic carbons in $\mathrm{C} 2$ also. The present synthesis method have been repeated three times and CQDs obtained were found reproducible and exhibiting amorphous behaviour, spherical morphology with particle size lying in the range of approx. 4$6 \mathrm{~nm}$ in diameter.

\subsection{Characterization of amine functionalized C1N and C2N}

The morphology and size of C1N and C2N were done by TEM and DLS. The TEM micrographs of C1N and C2N are shown in Fig. S3a and S3b† respectively. It is perceived that there is no remarkable change in size and morphology of $\mathrm{C} 1$ and $\mathrm{C} 2$ after amine functionalization. The $\mathrm{C} 1 \mathrm{~N}$ and $\mathrm{C} 2 \mathrm{~N}$ are still having spherical shape, well dispersity and uniform size.

The absorption study of $\mathrm{C} 1, \mathrm{C} 2, \mathrm{C} 1 \mathrm{~N}$ and $\mathrm{C} 2 \mathrm{~N}$ in aqueous medium was conducted using UV visible spectroscopy as presented in Fig. 4. C1 and C2 display the absorption band in the ultraviolet region due to the absorption of the aromatic $\pi$ system or the $n-\pi *$ transition of carbonyl groups which indicate the CQDs synthesis from soot (Fig. 4a). In the absorption spectra of EDA, the peaks at higher wavelengths $339 \mathrm{~nm}$ and $378 \mathrm{~nm}$ are mainly due to the presence of $\mathrm{C}-\mathrm{N}$ of amines. ${ }^{29-31}$

$\mathrm{C} 1$ absorbs at $220 \mathrm{~nm}$ while after amine functionalization of C1 with EDA (C2 : EDA: $1: 1 \mathrm{v} / \mathrm{v})$, the absorption peaks observed at $240 \mathrm{~nm}, 272 \mathrm{~nm}$ and $342 \mathrm{~nm}$ indicates the $\pi-\pi^{*}$ transition of the $\pi$-orbitals of aromatic carbon ( $\mathrm{C}=\mathrm{C}$ bond), $\mathrm{n}-\pi *$ transition of the $\mathrm{C}=\mathrm{O}$ and $\mathrm{C}=\mathrm{N}$ bond present in $\mathrm{C} 1 \mathrm{~N}$ QDs, respectively. ${ }^{32,33}$ The absorption in lower UV region is mainly due to polycyclic aromatic hydrocarbon (PAHs) with large energy band gaps (two or three ringed PAH). ${ }^{34}$

In the absorption spectra of $\mathrm{C} 2$, the broad peak from $262 \mathrm{~nm}$ to higher wavelength $300 \mathrm{~nm}$, indicates the $\pi-\pi^{*}$ transition of the $\pi$-orbitals of aromatic $\mathrm{C}=\mathrm{C}$ bond merged with the $\mathrm{n}-\pi^{*}$ transition of $\mathrm{C}=\mathrm{O}$ bond due to the possibly high carbonization by the oxidant, nitric acid during the synthesis of $\mathrm{C} 2{ }^{29-33}$ While after the treatment of $\mathrm{C} 2$ with $(15 \mu \mathrm{M})$ EDA (C2 : EDA: $40: 1 \mathrm{v} / \mathrm{v})$ a new peak at $337 \mathrm{mn}$ is credited to the $\mathrm{n}-\pi^{*}$ transition of $\mathrm{C}=\mathrm{N}$ bond which confirms the presence of nitrogen on the $\mathrm{C} 2 \mathrm{~N}$ surface. Moreover, after C2:EDA: $1: 1 \mathrm{v} / \mathrm{v}$ treatment, the increase in intensity and shifting of peak at $337 \mathrm{mn}$ to $342 \mathrm{~nm}$
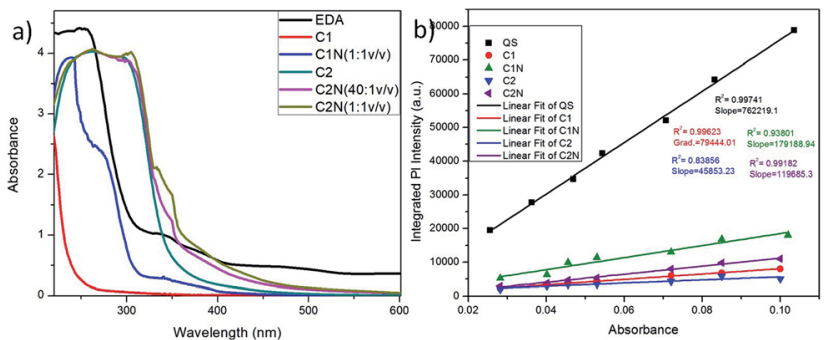

Fig. 4 (a) Absorption spectra of $\mathrm{C} 1, \mathrm{C} 2, \mathrm{C} 1 \mathrm{~N}$ and $\mathrm{C} 2 \mathrm{~N}$; and (b) quantum yield of $\mathrm{C} 1, \mathrm{C} 2, \mathrm{C} 1 \mathrm{~N}$ and $\mathrm{C} 2 \mathrm{~N}$. 
indicates the increase in nitrogen groups on the $\mathrm{C} 2 \mathrm{~N}$ surface. $^{29-33}$

This phenomenon lies on the fact that some auxochromes like amine groups that present on CQDs can result in the absorption peak at longer wavelengths. Therefore, the nitrogen containing unshared/lone pair of electrons could have reacted with the $\mathrm{C}=\mathrm{C}$ bonds which alone absorb at $280 \mathrm{~nm}$, while bonded together with nitrogen or oxygen $(\mathrm{C}=\mathrm{N}$ and/or $\mathrm{C}=\mathrm{O})$ absorbs at around $350 \mathrm{~nm}$. This phenomenon is involved in the structure of CQDs. ${ }^{35}$

The QY of these QDs was calculated using QS dye as reference (Fig. 4b). C1 exhibited the remarkable QY of $\sim 5.63 \%$ in comparison to $\mathrm{C} 2$ which delivers QY of $3.25 \%$. After their treatment with EDA, there was an increase in their QY i.e. from $5.63 \%$ of $\mathrm{C} 1$ to $12.7 \%$ for $\mathrm{C} 1 \mathrm{~N}$ and from $3.25 \%$ of $\mathrm{C} 2$ to $8.48 \%$ for C2N QDs. That can be attributed to the presence of auxochrome nitrogen having lone pair of electrons, on their surfaces after EDA treatment. The QY is approximate to here mention other works on CQDs synthesis from various other waste precursors in Table 1. In addition, our approach is expeditious, simplistic, and economic and utilizes one of the hazardous pollutant materials, vehicle soot as a precursor.

Upon excitation of $2 \mathrm{~mL} \mathrm{C} 1$ at different $\lambda_{\text {ex }}$ (from $220 \mathrm{~nm}$ to $370 \mathrm{~nm}$ ), it is observed that $\mathrm{C} 1$ shows highest emission intensity at $\lambda_{\mathrm{ex}}=240 \mathrm{~nm}\left(\lambda_{\mathrm{em}}=396 \mathrm{~nm}\right)$ which is due to the participation of $\mathrm{C}=\mathrm{C}$ of aromatic carbons along with little possible $\mathrm{C}=\mathrm{O}$ groups present in C1 QDs (Fig. 5a). The decrease in PL-intensity with increase in excitation wavelength can be targeted to a decrease in the absorption for higher wavelengths as shown in its absorption spectra.

$2 \mathrm{~mL} \mathrm{C2}$ solution was also excited at $\lambda_{\text {ex }}$ from $320 \mathrm{~nm}$ to $480 \mathrm{~nm}$. It was observed that $\mathrm{C} 2$ exhibit wavelength dependent emission behaviour i.e. from excitation wavelength $320 \mathrm{~nm}$ to $480 \mathrm{~nm}$, the emission wavelength red shift from $491 \mathrm{~nm}$ to $516 \mathrm{~nm}$ (Fig. $5 \mathrm{~b}$ and c). For $\lambda_{\mathrm{em}}=491 \mathrm{~nm}$ and $516 \mathrm{~nm}$, the excitation wavelength are $350 \mathrm{~nm}$ and $420 \mathrm{~nm}$ respectively that might be due to maximum numbers of particles are excited at $\lambda_{\mathrm{ex}}=350 \mathrm{~nm}$ and $420 \mathrm{~nm}$, resulting in maximum emission intensity. This red shift in emission behaviour could be attributed with the degree of oxidation and presence of multiple emission centres in these CQDs. ${ }^{36}$

Increasing the excitation wavelength has two striking effects on CQDs emission: a noteworthy decrease of the PL-intensity and a robust red shift. ${ }^{34}$ Here also, it can be noticed that, with increase in excitation wavelength, the overall emission intensity at $\lambda_{\mathrm{em}}=491 \mathrm{~nm}$ goes on decreasing while the intensity at $\lambda_{\mathrm{em}}=$ $516 \mathrm{~nm}$ keeps on increasing. The emission at lower excitation wavelength can be ascribed to C2 individual molecule singlet emission (singlet emission bands). When the excitation wavelength is increased from $400 \mathrm{~nm}$ to $480 \mathrm{~nm}$, two emission bands at $491 \mathrm{~nm}$ and $516 \mathrm{~nm}$ started narrowing. When the excitation wavelength is increased up to $480 \mathrm{~nm}$, these two becomes wellresolved peaks out of those bands at lower excitation wavelength. These bands are named as lower energy (LE) bands. ${ }^{34}$ It also indicates the presence of multiple absorption states in the sample which leads in the emission at higher wavelength. Exciting the CQDs at these secondary maxima led to intense asymmetric emission spectra with emission maxima at $516 \mathrm{~nm}$. These results elucidate that there are several different PAH molecules exist in the CQDs that are optically active in the spectral region of interest, and possible energy transfer happens between them. ${ }^{34}$ The main emission, might resulted from self-trapped excitons in PAHs while, the emission at longer wavelengths is likely emitted by PAHs with smaller energy band gaps.

It is reported that at shorter wavelengths $(<400 \mathrm{~nm})$ principally the three and four-ringed $\mathrm{PAH}$ (PAH-3R and $\mathrm{PAH}-4 \mathrm{R}$ respectively) are excited and either emits directly or, to a lesser scale, transfer energy to five-ringed PAH (PAH-5R). ${ }^{34}$ That might be due to the fact that at shorter wavelengths PAH5R do not absorb strongly so, the PAH-3R/4R might transfer their energy to the PAH-5R that account for the long emission tail seen at higher wavelengths. Upon the increase in $\lambda_{\text {ex }}$ to $400 \mathrm{~nm}$, all the PAHs (PAH-3R, PAH-4R and PAH-5R) can be excited directly, leads in red shift of emission wavelength. Beyond this $\left(\lambda_{\mathrm{ex}}>400 \mathrm{~nm}\right)$, the PAH-3R and PAH-4R show less absorption and while the PAH-5Rexhibit increased absorption, resulting in a constant shift of the PL emission. ${ }^{34}$ This emission behaviour is in agreement with other foregoing published multicolour imaging applications of CQDs. ${ }^{34,37}$

So, it can be summarized that, $\mathrm{C} 1$ might be composed of PAHs as in order of PAH-3R $>$ PAH-4R > PAH-5R; while, C2 might comprise of the PAHs as sequence of PAH- $4 \mathrm{R}>\mathrm{PAH}-3 \mathrm{R}>$ PAH-5R which are responsible for their specific emission behaviour. Both of the QDs are having lesser PAHs having lower band gap energies (PAH-5R), while the amount of PAH-4R is considerably higher in $\mathrm{C} 2$ than that of $\mathrm{C} 1$ as depicted from their emission profiles. This can be credited to the nitric acid treatment during the synthesis of $\mathrm{C} 2$. On the basis of this finding, the expected structure and their optical phenomenon of $\mathrm{C} 1$ and

Table 1 Comparative analysis of these CQDs with a few of best reported CQDs synthesized from greener route regarding their quantum yield and other parameters

\begin{tabular}{|c|c|c|c|c|}
\hline Precursor & Synthesis & QY\% & Application & Reference \\
\hline Soy milk & Hydrothermal & 0.026 & Electrocatalysis & 13 \\
\hline Sugarcane juice & Hydrothermal & 0.057 & Cell-imaging & 14 \\
\hline Coffee & DI water, centrifugation & 5.5 & Cell-imaging & 15 \\
\hline Egg yolk & Plasma-induced pyrolysis & 5.96 & Fluorescent ink & 16 \\
\hline Dextrin & $\mathrm{H}_{2} \mathrm{O}+\mathrm{H}_{2} \mathrm{SO}_{4}$, microwave-assisted & $4.8-8.4$ & Cell imaging & 17 \\
\hline \multirow[t]{2}{*}{ Vehicle soot } & Water & 5.63 & TNT sensing & This work \\
\hline & Nitric acid & 3.25 & & \\
\hline
\end{tabular}



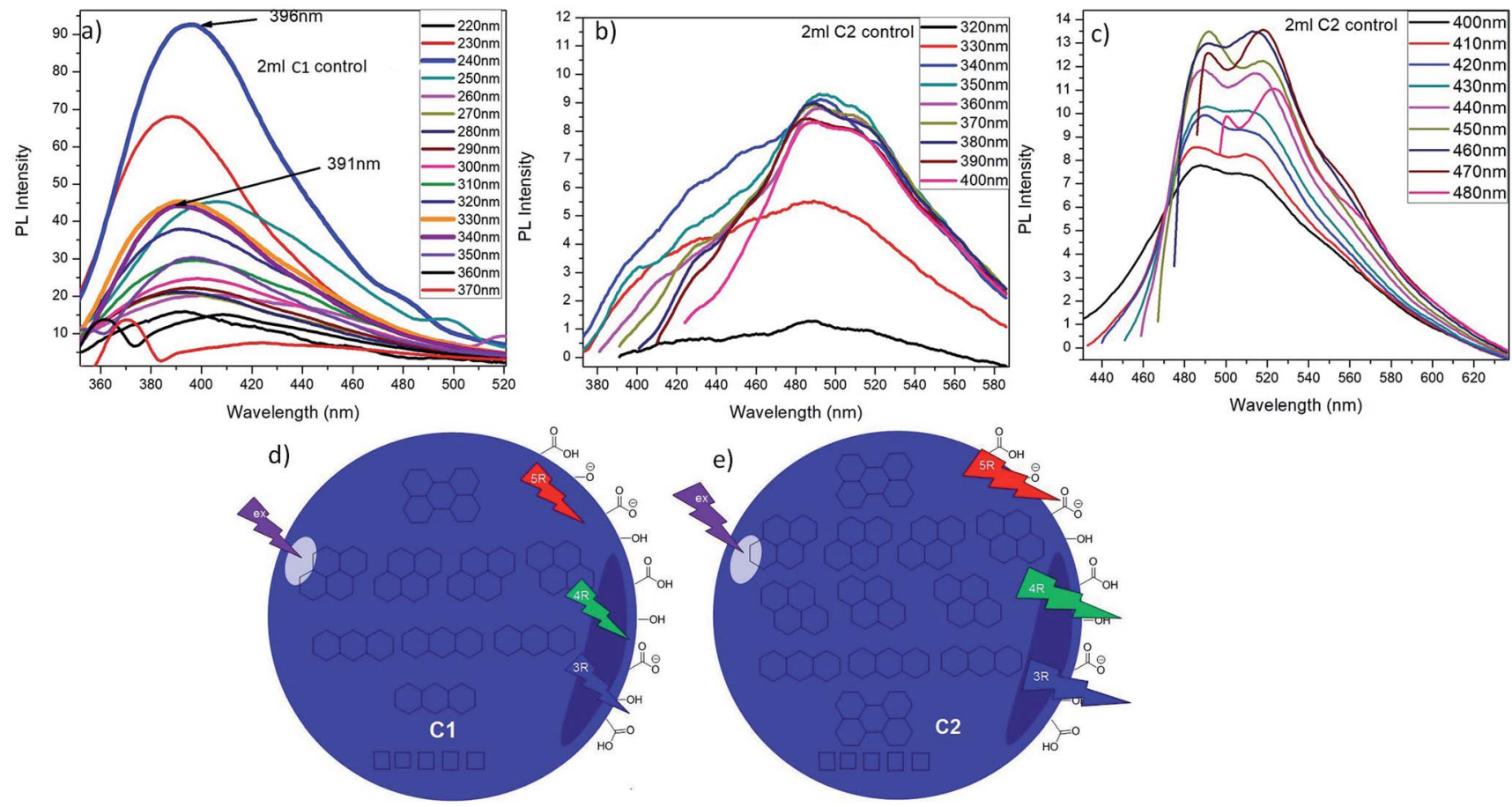

Fig. 5 Showing the PL emission spectra of (a) C1; (b) and (c) C2 at different excitation wavelengths; (d) and (e) are the proposed compositions of $\mathrm{C} 1$ and $\mathrm{C} 2$ respectively on the basis of the number of rings in PAHs.

$\mathrm{C} 2$ are elucidated in Fig. 5d and e respectively. C1 and C2 dissolved in water solvent were observed to be stable at room temperature for at least eight months.

The amine capped CQDs were further characterized for their emission behaviour (Fig. 6). As discussed here, C1 were observed to possess higher emission intensity at $\lambda_{\mathrm{ex}}=240 \mathrm{~nm}$ but after EDA treatment, the maximum change in their emission intensity was observed at $\lambda_{\text {ex }}=340 \mathrm{~nm}$. So, these two excitation wavelengths were considered for assessment of change in emission intensity of $\mathrm{C} 1$ after amine
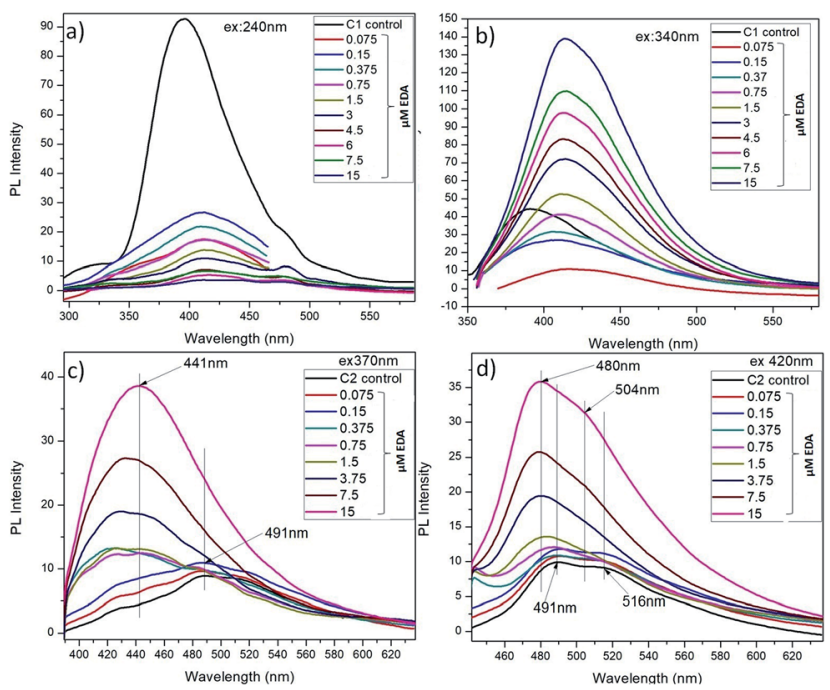

Fig. 6 Showing the PL emission spectra of C1 (a) and (b); C2 (c) and (d) in the presence of EDA at different excitation wavelengths respectively. functionalization (Fig. 6a and b). It was observed that at $\lambda_{\mathrm{ex}}=$ $240 \mathrm{~nm}$, there is decrease in emission intensity with the increase in EDA concentration and simultaneously, red shift in emission wavelength from $\lambda_{\mathrm{em}}=396 \mathrm{~nm}$ in absence of EDA to $\lambda_{\mathrm{em}}=414 \mathrm{~nm}$ in presence of 7.5 $\mu \mathrm{M}$ EDA. Concurrently, at $\lambda_{\mathrm{ex}}=$ $340 \mathrm{~nm}$, a continuous increase in emission intensity $\left(\lambda_{\mathrm{em}}=414\right.$ $\mathrm{nm}$ ) was observed with the increase in EDA concentration. Finally, there is approximate complete loss of $\mathrm{C} 1$ emission intensity in the presence of higher EDA $(15 \mu \mathrm{M})$ concentration. It clearly depicts the involvement of oxygen-containing functional groups i.e. $(\mathrm{C}=\mathrm{O}) / \mathrm{C}-\mathrm{OH}$ at the surface of $\mathrm{C} 1$ in bonding with the amine groups of EDA leading in the net decrease in free $\mathrm{C}=\mathrm{O} / \mathrm{C}-\mathrm{OH}$ groups. Finally, it is assumed that in the presence of $15 \mu \mathrm{M}$ EDA, approximate the entire free $\mathrm{C}=\mathrm{O} / \mathrm{C}-\mathrm{OH}$ groups are used in amine functionalization. The redshift and increase in emission intensity at $\lambda_{\mathrm{ex}}=240 \mathrm{~nm}$ and $340 \mathrm{~nm}\left(\lambda_{\mathrm{em}}=414\right.$ $\mathrm{nm}$ ) respectively confirm the generation of $\mathrm{C}-\mathrm{N} / \mathrm{C}=\mathrm{N}$ groups on C1 surface. $^{38}$

As explained before, due to the different PAHs distribution in $\mathrm{C} 2$, they exhibit emission at higher wavelengths i.e. $\lambda_{\mathrm{em}}$ shifts from $491 \mathrm{~nm}$ to $516 \mathrm{~nm}$ with increase in $\lambda_{\mathrm{ex}}$ from $320 \mathrm{~nm}$ to $480 \mathrm{~nm}$. After EDA treatment, it is observed that at $\lambda_{\text {ex }} 370 \mathrm{~nm}$ and $420 \mathrm{~nm}$, there is an increase in emission intensity and the remarkable shift in emission wavelength of $\mathrm{C} 2$ towards the short wavelength with the increase in EDA concentration (Fig. $6 \mathrm{c}$ and d). There is an extreme decrease in the carboncarbon bonds $(\mathrm{C}=\mathrm{C} / \mathrm{C}-\mathrm{C})$ with the increase in nitrogen-based dopant concentration. ${ }^{38}$ On the other side, the carbon-oxygen bonds $((\mathrm{C}=\mathrm{O}) / \mathrm{C}-\mathrm{OH})$ and carbon-nitrogen bonds $(\mathrm{C}-\mathrm{N} / \mathrm{C}=\mathrm{N})$ increase with increase of the nitrogen-based dopant concentration. So, this observed increase in emission intensity of $\mathrm{C} 2$ 
after EDA treatment, can be attributed to the generation of C-N/ $\mathrm{C}=\mathrm{N}$ bonds on $\mathrm{C} 2$ surface after EDA treatment. ${ }^{9,38}$ Along with, the shifting of maximum emission peak toward the short wavelength might be due to the decrease in $\mathrm{C}=\mathrm{C} / \mathrm{C}-\mathrm{C}$ bonds with the increase in EDA concentration which could have change in PAHs distribution in $\mathrm{C} 2$ as: $\mathrm{PAH}-3 \mathrm{R}>\mathrm{PAH}-4 \mathrm{R}$.

The work reported in literature (ref. 39-43) explain different mechanism for the strong photoluminescence of luminescent carbon dots but convincing photoluminescence mechanism is still unclear. In present work QD were functionalized with EDA to subject amine group on their surface using different concentration of EDA maintained at $\mathrm{pH}$ in the range of 6.5-7. In protonated EDA-QDs, a cyclic structure might have formed through the H-bonding between $\mathrm{NH}^{3+}$ and the oxygen atom of the amide bond. Moreover, explanation for possible presence and distribution of PAHs in CQDs were already have been discussed in manuscript. These conjugated polyaromatic structure are involved in this EDA mediated CQDs emission enhancement. The cyclic structure formed by protonated EDA might have aided the indirect proton transfer from $\mathrm{NH}^{3+}$ to the conjugated PAHs through the carboxyl groups. This proton transfer would have prevented the charge transfer in the excited state resulting in the recovery of fluorescence. ${ }^{9}$

So, it can be summarized that EDA terminal nitrogen contributes its extra electrons into the $\pi$-electron system of CQDs through the carboxyl groups and instigate a change in the densities of $\pi$ states. ${ }^{44}$ It may result to an increment of the energy states density near the Fermi levels which enhances the emission intensities in the $\mathrm{C} 1 \mathrm{~N}$ and $\mathrm{C} 2 \mathrm{~N}$. The proposed explanation is also evidenced by the work reported by Z. Qian et al. ${ }^{9}$

These N-capped CQDs (C1N and C2N) are then inspected for TNT detection. Since, the electron deficient ring of TNT can form JM complex with the amine groups of EDA, so this complex is explored for the overlapping behaviour between the absorption spectrum of JM complex and the emission spectrum of C1N in the presence of TNT. Fig. 7a shows the possible overlapping of absorbance spectrum of EDA/TNT (JM complex) with the emission spectra of C1, C1N and C1NT ( $220 \mu \mathrm{M}$ TNT). The broad absorption peak of EDA/TNT at longer wavelength confirms the formation of JM complex between amine groups of EDA and electron deficient ring of TNT. It unveils that due to good spectral overlapping between the absorbance of EDA/TNT (JM complex) with the emission of C1N, justifying that C1NT possess high tendency to quench the C1N emission. Fig. 7a shows the abrupt decrease in PL intensity of $\mathrm{C} 1 \mathrm{~N}$ on addition of $220 \mu \mathrm{M}(50 \mathrm{ppm}) \mathrm{TNT}$, which involves the surface amine groups capable to interact with TNT. The possible rationale behind this PL emission quenching relies on the formation of Meisenheimer complex (JM-complex) by electron-rich amine groups of $\mathrm{C} 1 \mathrm{~N}$ with electron deficient TNT aromatic ring. This JM complex (C1NT) absorbs at the emission wavelength of C1N. This behaviour is in successful approach for TNT detection using C1N.

Accordingly, a successive decrease in $\mathrm{C} 1 \mathrm{~N}$ emission intensity is spotted with the increase in TNT concentration from $44 \mathrm{nM}$ to $220 \mu \mathrm{M}$ in $\mathrm{C} 1 \mathrm{~N}$ solution at $\lambda_{\text {ex }}=340 \mathrm{~nm}$ (Fig. $7 \mathrm{~b}$ ). The percentage quenching $(\mathrm{Q} \%)$ can be demonstrated as:
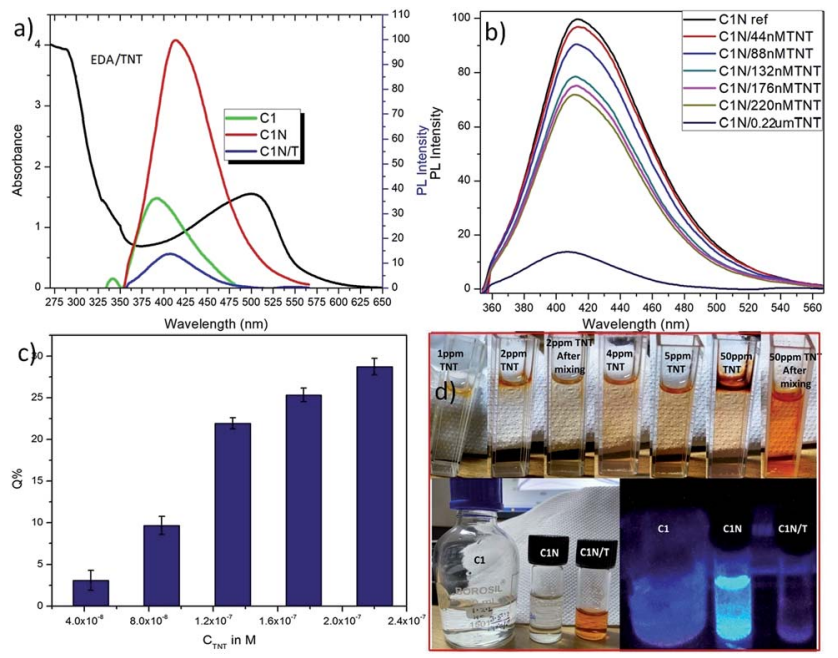

Fig. 7 (a) Overlapping of absorbance spectra of EDA/TNT with emission spectra of C1, C1N and C1NT; (b) analytical performance of C1N towards TNT in $220 \mu \mathrm{M}$ to $44 \mathrm{nM}$ concentration range; (c) percentage quenching of C1N fluorescence in presence of TNT; and (d) photographs of $\mathrm{C} 1 \mathrm{~N}$ solutions in ambient light (upper panel) showing the colorimetric change with increase in TNT concentration and under UV illumination (lower right panel) in the absence and presence of TNT.

$$
Q \%=\left[\frac{\left(I_{0}-I\right)}{I_{0}}\right] \times 100
$$

where $I$ and $I_{0}$ represent the fluorescence emission intensities of the donor $\mathrm{N}$-capped CQDs (C1N or $\mathrm{C} 2 \mathrm{~N}$ in respective case) in the presence and absence of the acceptor TNT, respectively. The resultant Q\% by TNT on the C1N fluorescence emission is found to be proportional to the TNT concentration. The increase in $\mathrm{Q} \%$ of $\mathrm{C} 1 \mathrm{~N}$ emission intensity from $3.3 \%$ to $28.73 \%$ is delivered as the TNT concentration is increased from $4.4 \times 10^{-8} \mathrm{M}(0.01$ ppm) to $2.2 \times 10^{-7} \mathrm{M}(0.05 \mathrm{ppm})$ (Fig. $\left.7 \mathrm{c}\right)$. The upper panel of Fig. 7d shows the colorimetric changes in the $\mathrm{C} 1 \mathrm{~N}$ solution with the addition of TNT. It depicts that with the increase in TNT concentration, there is sharp and clear change in the colour of C1N solution from the colourless to orange like colour of C1NT. The photographs of C1, C1N and C1NT solutions in ambient light and under UV illumination are shown in the lower left and right panel of Fig. 7d respectively. It definitely portrays that in the TNT results in sharp quenching in $\mathrm{C} 1 \mathrm{~N}$ emission.

The theoretical interpretation of the TNT detection capability of C1N in terms of detection limit (LOD), Stern-Volmer constant $\left(K_{\mathrm{SV}}\right)$ and the association constant of $\mathrm{C} 1 \mathrm{~N}$ and TNT by Benesi-Hildebrand method is presented in Fig. 8a, b and c respectively. The LOD of C1N based probe towards TNT was determined using the relation of change in fluorescent intensity $\left(I_{0}-I\right)$ at $\lambda_{\mathrm{em}}=414 \mathrm{~nm}$ against TNT concentration (in M) (signal to noise ratio $=3$ ) (Fig. 8a). The limit of detection is calculated using:

$$
\mathrm{LOD}=\frac{k \times \mathrm{SD}}{b}
$$

where $k=3$; SD represents the standard deviation in the change in emission intensity of the blank at $414 \mathrm{~nm}$ and ' $b$ ' is the slope 

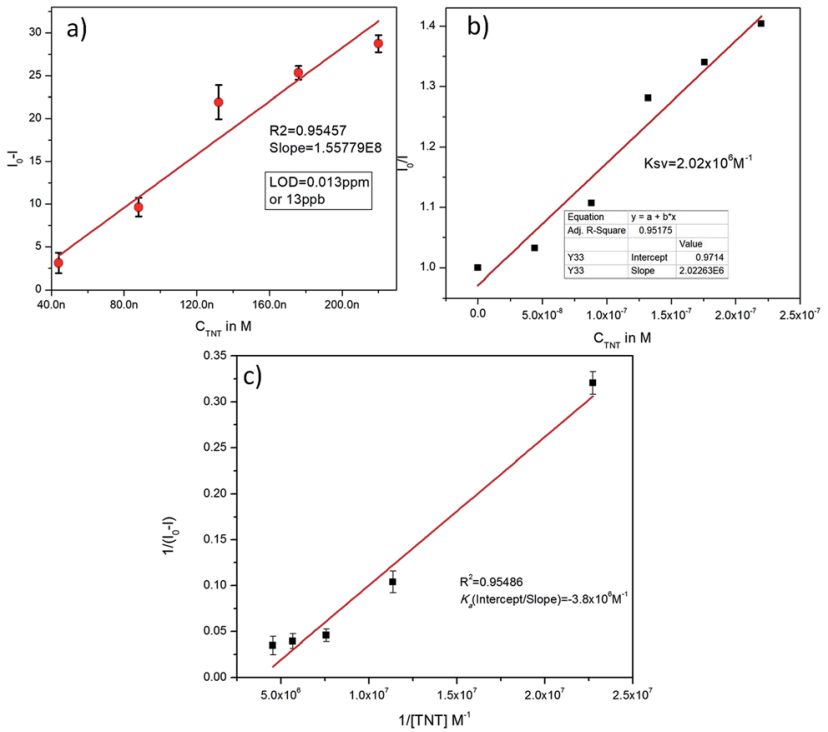

Fig. 8 (a) Analysis of variation in fluorescence emission intensity of C1N towards TNT in $4.4 \times 10^{-8} \mathrm{M}$ to $2.2 \times 10^{-7} \mathrm{M}$ concentration range; (b) Stern-Volmer plot of C1N fluorescence against of TNT concentration; and (c) relation between $1 / I_{0}-I$ and $1 /$ TNT attributing the association constant of $\mathrm{C} 1 \mathrm{~N}$ and TNT by Benesi-Hildebrand method.

of the regression line. A distinct linear decrease in C1N emission in presence of TNT in the concentration range of $44 \mathrm{nM}$ to $220 \mathrm{nM}$ with $R^{2}=0.954(n=3)$. The linear regression equation can be represented as:

$$
\Delta I=I_{0}-I=1.557 \times 10^{8} C
$$

(where $C$ stands for TNT concentration in $\mathrm{M}$ ) as evidenced in Fig. 8a. Having SD of \pm 3.0308 in emission intensity at $414 \mathrm{~nm}$, this $\mathrm{C} 1 \mathrm{~N}$ based nanoprobe delivered a very low LOD of about $13 \mathrm{ppb}$ TNT.

Under the controlled conditions, the TNT induced PL quenching caused is excellently expressed by the Stern-Volmer equation:

$$
\frac{I_{0}}{I}=K_{\mathrm{SV}}(Q)+C
$$

where $I_{0}$ and $I$ represent the PL emission intensity in the absence and presence of TNT, respectively, $K_{\mathrm{SV}}$ is the SternVolmer constant standing for the affinity between donor and acceptor/quencher analyte, $Q$ means for TNT concentration, and $C$ is a constant having the value $\sim 1$. The $K_{\mathrm{SV}}$ is found to be $2.02 \times 10^{6} \mathrm{M}^{-1}$ in the concentration range of $0 \mathrm{nM}$ to $220 \mathrm{nM}$ plotted against $I_{0} / I$ (Fig. 8b). The linear regression equation $\left(R^{2}\right.$ $=0.95175$ ) for change in emission intensity of C1N with TNT concentration can be written as:

$$
\frac{I_{0}}{I}=2.02263 \times 10^{6} Q+0.9714
$$

The association constant of the TNT-C1N complex is determined by Benesi-Hildebrand method (Fig. 8c) from its PL emission quenching data following the equation:

$$
\frac{1}{\left(I_{0}-I\right)}=\frac{1}{\left(I_{0}-I_{\mathrm{b}}\right)}+\frac{1}{K_{\mathrm{a}}\left(I_{0}-I_{\mathrm{b}}\right)[\mathrm{TNT}]}
$$

where $K_{\mathrm{a}}$ stands for the apparent association constant; $I_{0}$ and $I_{\mathrm{b}}$ are the emission intensity of C1N in the absence of TNT and in the presence of TNT excess; and I means the observed emission intensity of $\mathrm{C} 1 \mathrm{~N}$ in the presence of varied TNT concentrations. The $1 /\left(I_{0}-I\right)$ value is plotted against $1 /[\mathrm{TNT}]$ to calculate the $K_{\mathrm{a}}$ value, which is equal to the intercept/slope (Fig. 8c). $K_{\mathrm{a}}$ is obtained as $-3.8 \times 10^{6} \mathrm{M}^{-1}$ showing the high sensitivity of C1N for TNT.

Sustaining the same principle for TNT detection on the basis of JM complex formation with the amine groups present on CQDs surface, C2N was also explored for TNT detection (Fig. 9). In agreement with the $\mathrm{C} 1 \mathrm{~N}$ results, $\mathrm{C} 2 \mathrm{~N}$ emission intensity is also witnessed to decrease successively with the increase in TNT concentration from $4.4 \times 10^{-8} \mathrm{M}$ to $3.08 \times 10^{-7} \mathrm{M}(44 \mathrm{nM}$ to $308 \mathrm{nM}$ ) concentration range at both the excitation wavelengths $370 \mathrm{~nm}$ and $420 \mathrm{~nm}$ (Fig. 9a and c). The $Q \%$ for $\mathrm{C} 2 \mathrm{~N}$ in the presence of TNT at $\lambda_{\mathrm{ex}}=340 \mathrm{~nm}$ and $420 \mathrm{~nm}$ are shown in the insets of Fig. $9 \mathrm{~b}$ and d respectively. At the $\lambda_{\mathrm{ex}}=340 \mathrm{~nm}$, the net $Q \%$ of the $\mathrm{C} 2 \mathrm{~N}$ emission intensity by TNT is found to be about $15.55 \%$ and $9.29 \%$ at $2.64 \times 10^{-7} \mathrm{M}(0.06 \mathrm{ppm})$ and $4.4 \times$ $10^{-8} \mathrm{M}(0.01 \mathrm{ppm})$ TNT concentrations respectively (Fig. 9b inset). While at the $\lambda_{\mathrm{ex}}=420 \mathrm{~nm}$, the aggregate $Q \%$ of the $\mathrm{C} 2 \mathrm{~N}$ emission intensity by TNT is about $21.64 \%$ and $16.25 \%$ at 2.64 $\times 10^{-7} \mathrm{M}(0.06 \mathrm{ppm})$ and $8.8 \times 10^{-8} \mathrm{M}(0.02 \mathrm{ppm}) \mathrm{TNT}$ concentrations respectively (Fig. $9 \mathrm{~d}$ inset). In inferior to the $\mathrm{C} 1 \mathrm{~N}$, there is no visible colorimetric change in $\mathrm{C} 2 \mathrm{~N}$ solution upon the addition of TNT. As explained here, there is only the change in C2N PL emission intensity in the presence of TNT due to quenching phenomenon.

The LOD of C2N nanoprobe respecting TNT is also evaluated using the relation between $I_{0}-I$ at emission wavelengths
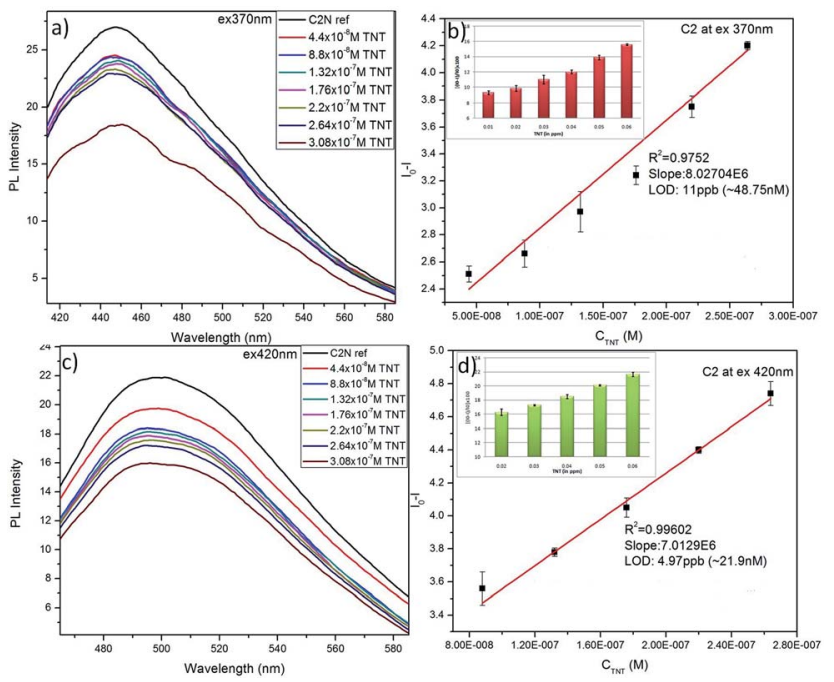

Fig. 9 (a) and (c) Analytical performance of C2N towards TNT in 3.08 $\times 10^{-7} \mathrm{M}$ to $4.4 \times 10^{-8} \mathrm{M}$ concentration range at $\lambda_{\text {ex }} 370 \mathrm{~nm}$ and $420 \mathrm{~nm}$ respectively; (b) and (d) analysis of variation in fluorescence emission intensity of C2N towards TNT for LOD determination; inset of (b) and (d): Q\% of C2N fluorescence in presence of TNT at $\lambda_{\text {ex }} 370 \mathrm{~nm}$ and $420 \mathrm{~nm}$ respectively. 

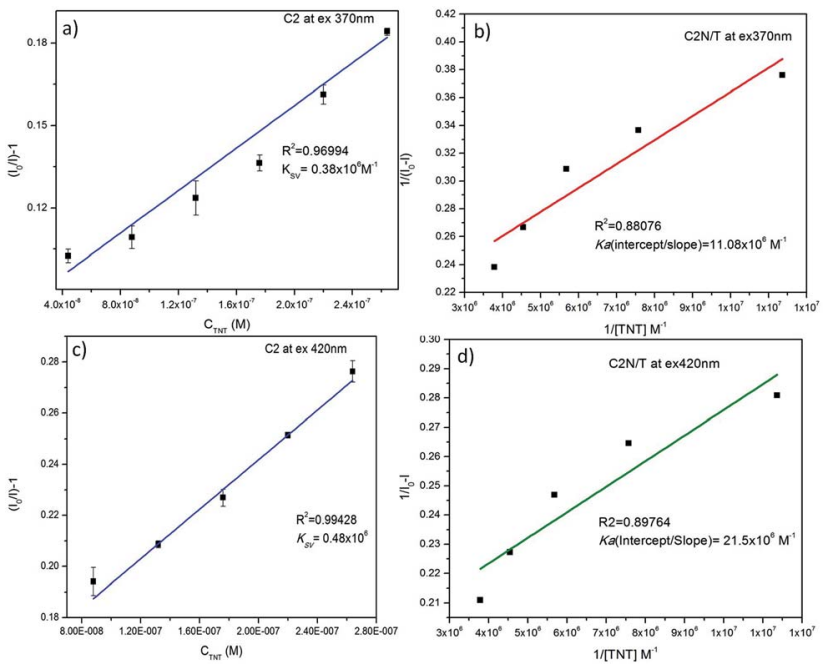

Fig. 10 (a) and (c) Stern-Volmer plot of C2N fluorescence against of TNT concentration at $\lambda_{\text {ex }} 370 \mathrm{~nm}$ and $420 \mathrm{~nm}$ respectively; (b) and (d) relation between $1 / I_{0}-1$ and $1 /$ TNT attributing the association constant of C2N and TNT at $\lambda_{\text {ex }} 370 \mathrm{~nm}$ and $420 \mathrm{~nm}$ respectively by Benesi-Hildebrand method.

$447 \mathrm{~nm}$ (for $\lambda_{\text {ex }}=370 \mathrm{~nm}$ ) and $498 \mathrm{~nm}\left(\lambda_{\text {ex }}=420 \mathrm{~nm}\right)$ against TNT concentration (in $\mathrm{M})(n=3)$ as shown in Fig. $9 \mathrm{~b}$ and $\mathrm{d}$ respectively. At both the $\lambda_{\mathrm{ex}}$, a clear linear decrease in $\mathrm{C} 2 \mathrm{~N}$ emission intensity due to TNT is observed.

At $\lambda_{\mathrm{ex}}=370 \mathrm{~nm}$, the linear TNT concentration range is $4.4 \times$ $10^{-8} \mathrm{M}$ to $2.64 \times 10^{-7} \mathrm{M}$ while, at $\lambda_{\mathrm{ex}}=420 \mathrm{~nm}$, it is $8.8 \times$ $10^{-8} \mathrm{M}$ to $2.64 \times 10^{-7} \mathrm{M}$. Their linear regression equation can be represented as:

$$
\begin{array}{r}
\text { At } \lambda_{\mathrm{ex}}=370 \mathrm{~nm}:\left(R^{2}=0.9752 ; \mathrm{SD} \text { is } \pm 0.13\right), \\
\Delta I=I_{0}-I=8.027 \times 10^{6} \mathrm{C} .
\end{array}
$$

$$
\text { At } \lambda_{\mathrm{ex}}=420 \mathrm{~nm}:\left(R^{2}=0.996 ; \mathrm{SD} \text { is } \pm 0.0512\right) \text {, }
$$

$$
\Delta I=I_{0}-I=7.013 \times 10^{6} \mathrm{C}
$$

(where $C$ stands for TNT concentration in $\mathrm{M}$ ). So, this $\mathrm{C} 2 \mathrm{~N}$ based nanoprobe is found to achieve the very low LOD of about $11 \mathrm{ppb}$ TNT at $\lambda_{\mathrm{ex}}=370 \mathrm{~nm}$ and $4.97 \mathrm{ppb}$ TNT at $\lambda_{\mathrm{ex}}=420 \mathrm{~nm}$.

The $K_{\mathrm{SV}}$ and $K_{\mathrm{a}}$ of $\mathrm{C} 2 \mathrm{~N}$ in the presence of TNT at both the excitation wavelengths ( $\lambda_{\mathrm{ex}} 370 \mathrm{~nm}$ and $420 \mathrm{~nm}$ ) are also calculated as presented in Fig. 10. When $I_{0} / I$ is plotted against the TNT concentration (in M), the $K_{\mathrm{SV}}$ for $\mathrm{C} 1 \mathrm{~N}$, at $\lambda_{\mathrm{ex}} 370 \mathrm{~nm}$ is calculated as $0.38 \times 10^{6} \mathrm{M}^{-1}\left(R^{2}=0.96994\right)$ in the concentration range of is $4.4 \times 10^{-8} \mathrm{M}$ to $2.64 \times 10^{-7} \mathrm{M}$ (Fig. 10a) while at $\lambda_{\text {ex }} 420 \mathrm{~nm}$, it is found to be $0.48 \times 10^{6} \mathrm{M}^{-1}\left(R^{2}=0.99428\right)$ in the concentration range of is $8.8 \times 10^{-8} \mathrm{M}$ to $2.64 \times 10^{-7} \mathrm{M}$ (Fig. 10c). The $K_{\mathrm{a}}$ value for $\mathrm{C} 2 \mathrm{~N}$ with TNT at $\lambda_{\mathrm{ex}} 370 \mathrm{~nm}$ and $420 \mathrm{~nm}$ are found as $11.08 \times 10^{6} \mathrm{M}^{-1}$ (Fig. 10b) and $21.5 \times 10^{6}$ $\mathrm{M}^{-1}$ (Fig. 10d) respectively. These high values of $K_{\mathrm{a}}$ for C1N and C2N implicate their high sensitivity towards TNT. This experimental data certainly enlightens the effective energy transfer between nitrogen capped CQDs and JM complex in the solution leading to increased fluorescence quenching.

The comparison of $\mathrm{C} 1 \mathrm{~N}$ and $\mathrm{C} 2 \mathrm{~N}$ (at $\lambda_{\mathrm{ex}} 370 \mathrm{~nm}$ and $420 \mathrm{~nm}$ ) in the terms of different theoretical properties among each other is shown in Table S1. $\dagger$ The LOD and $K_{\mathrm{SV}}$ for both the C1N and $\mathrm{C} 2 \mathrm{~N}$ are in the vicinity of or lower than the most sensitive reported fluorescent quenching methods as listed in Table 2.

The amine-terminated compound (EDA) acts as surface passivating agent for CQDs. The surface passivation is required for the enhanced photoluminescence (PL) of the CQDs. ${ }^{27}$ The reason for enhanced sensitivity might be that we modified the CQDs surface with short length EDA molecules. It is known that the resultant spacer length in several nanometers around nanoparticles surface has an adverse effect on the energy transfer efficiency between donor and acceptor. ${ }^{50}$ The choice of EDA for the modification of CQDs surface is crucial, because it not only allows a compact surface structure but also provides higher binding sites for TNT molecules to form JM complex. ${ }^{45}$ The strong donor-acceptor (D-A) interactions between the JM complex formed by TNT with the EDA at the CQDs surface induced significant quenching in CQDs emission and enabled easily detection of ultra-trace TNT.

The XRD spectra and Raman spectra are shown and discussed in Fig. S2 of ESI. $\dagger$ The TEM micrographs of C1N and C2N are shown in Fig. S3. $\dagger$ The hydrodynamic size and surface potentials of $\mathrm{C} 1$ and $\mathrm{C} 2$ before and after amine functionalization were measured by DLS and shown in Fig. S4 and S5 $\dagger$ respectively. The FTIR study was conducted to confirm the EDA functionalization of C1, C2 QDs and their interactions with TNT as discussed in ESI (Fig. S6 $\dagger$ ). The EDX data is shown in Fig. S7. $\dagger$ The systematic execution of $\mathrm{C} 1 \mathrm{~N}$ and $\mathrm{C} 2 \mathrm{~N}$ concerning their selectivity towards TNT was also conducted against some of the very common interfering TNT analogues such as DNT, 2-TA, and NB which is also discussed in ESI (Fig. S8†). Owing to the high sensitivity and selectivity delivered by these CQDs probes

\begin{tabular}{|c|c|c|c|c|}
\hline S. No. & System & LOD & $K_{\mathrm{SV}}$ & Ref. \\
\hline 1 & Vehicle soot derived CQDs & $\sim 4.9$ ppb & $0.48 \times 10^{6} \mathrm{M}^{-1}$ & This work \\
\hline 2 & Oligohistidine-CdSe-ZnS QDs & $19.98 \mathrm{ppb}$ & $0.17 \times 10^{6} \mathrm{M}^{-1}$ & 45 \\
\hline 3 & Poly(p-phenylenevinylene)/mesoporous silica nanoparticles & $136 \mathrm{ppb}$ & $0.011 \times 10^{6} \mathrm{M}^{-1}$ & 46 \\
\hline 4 & Graphene QDs & $490 \mathrm{ppb}$ & $8 \times 10^{3} \mathrm{M}^{-1}$ & 47 \\
\hline 5 & (FITC- $\beta$-cyclodextrin) & $4.5 \mathrm{ppb}$ & $0.379 \times 10^{6} \mathrm{M}^{-1}$ & 48 \\
\hline 6 & Porphyrin-doped mesoporous silica & $10 \mathrm{ppb}$ & Not studied & 49 \\
\hline
\end{tabular}
(C1N and C2N), their feasibility was also vindicated against real tap water samples (CSIO) impaled with TNT [data shown in

Table 2 Comparison of this method with some reported works on fluorescence based TNT detection in terms of LOD and $K_{\mathrm{SV}}$ 
Table S2†]. The cell compatibility study (MTT assay) and their potential for TNT detection in cells is also discussed in ESI (Fig. S9†).

\section{Conclusions}

Vehicle soot, one of the hazardous pollutants has been explored as starting material for CQDs synthesis with a facile hydrothermal method. The CQDs has been synthesized in the absence and presence of oxidant, $\mathrm{HNO}_{3}$ to check the influence of presence of oxidant on the emission profile of these CQDs. The as-synthesized CQDs were amine functionalized using EDA as capping agent. A remarkable increase in their QY was observed after EDA treatment. The presence of nitrogen moieties on CQDs surface was confirmed by UV, PL and FTIR spectroscopy. It was expected that, $\mathrm{C} 1$ might be composed of PAHs as in order of PAH-3R > PAH-4R > PAH-5R; while, C2 might comprise of the PAHs as sequence of PAH- $4 \mathrm{R}>\mathrm{PAH}-3 \mathrm{R}>\mathrm{PAH}-$ $5 \mathrm{R}$ which are responsible for their specific emission behaviour. The amine groups present on $\mathrm{C} 1 \mathrm{~N}$ and $\mathrm{C} 2 \mathrm{~N}$ surfaces were involved in the formation of Meisenheimer complex with TNT for its monitoring in spiked water up to sub-ppb level (minimum $\sim 4.97 \mathrm{ppb}$ TNT). Both the C1N and C2N (at $\lambda_{\mathrm{ex}}=$ $370 \mathrm{~nm}$ and $\lambda_{\mathrm{ex}}=420 \mathrm{~nm}$ ) exhibited high sensitivity and selectivity towards TNT with higher values of both the $K_{\mathrm{Sv}}$ and $K_{\mathrm{a}}$. The results are in line with the waste to wealth approach (soot to shine), wherein the hazardous pollutant vehicle product is approached as a detection probe for explosive sensing. The study also documented the applicability of these CQDs for intracellular TNT detection.

\section{Conflicts of interest}

Authors declare that there is not any conflict of interest.

\section{Acknowledgements}

The authors acknowledge Director, CSIR-CSIO, Chandigarh for his kind permission to perform this work.

\section{References}

$1 \mathrm{~J}$. T. Hardy, Climate change: causes, effects, and solutions, John Wiley \& Sons, 2003.

2 H. Feng and Z. Qian, The Chemical Record, 2018, 18, 491-505.

3 G. Chen, H. Feng, X. Jiang, J. Xu, S. Pan and Z. Qian, Anal. Chem., 2018, 90, 1643-1651.

4 C. Tang, J. Zhou, Z. Qian, Y. Ma, Y. Huang and H. Feng, J. Mater. Chem. B, 2017, 5, 1971-1979.

5 J. Hou, H. Cheng, C. Yang, O. Takeda and H. Zhu, Nano Energy, 2015, 18, 143-153.

6 Y.-Q. Zhang, D.-K. Ma, Y.-G. Zhang, W. Chen and S.-M. Huang, Nano Energy, 2013, 2, 545-552.

7 C.-B. Ma, Z.-T. Zhu, H.-X. Wang, X. Huang, X. Zhang, X. Qi, H.-L. Zhang, Y. Zhu, X. Deng and Y. Peng, Nanoscale, 2015, 7, 10162-10169.
8 D. G. Babar, S. K. Sonkar, K. M. Tripathi and S. Sarkar, J. Nanosci. Nanotechnol., 2014, 14, 2334-2342.

9 Z. Qian, J. Ma, X. Shan, L. Shao, J. Zhou, J. Chen and H. Feng, RSC Adv., 2013, 3, 14571-14579.

10 J.-e. Park, E. D. Grayfer, Y. Jung, K. Kim, K.-K. Wang, Y.-R. Kim, D. Yoon, H. Cheong, H.-E. Chung and S.-J. Choi, J. Mater. Chem. B, 2013, 1, 1229-1234.

11 X. T. Zheng, H. L. He and C. M. Li, RSC Adv., 2013, 3, 2485324857.

12 S. Devi, A. Kaur, S. Sarkar, S. Vohra and S. Tyagi, Integr. Ferroelectr., 2018, 186, 32-39.

13 C. Zhu, J. Zhai and S. Dong, Chem. Commun., 2012, 48, 93679369.

14 V. N. Mehta, S. Jha and S. K. Kailasa, Mater. Sci. Eng., C, 2014, $38,20-27$.

15 C. Jiang, H. Wu, X. Song, X. Ma, J. Wang and M. Tan, Talanta, 2014, 127, 68-74.

16 J. Wang, C. F. Wang and S. Chen, Angew. Chem., Int. Ed., 2012, 51, 9297-9301.

17 N. Puvvada, B. N. P. Kumar, S. Konar, H. Kalita, M. Mandal and A. Pathak, Sci. Technol. Adv. Mater., 2012, 13, 045008.

18 S. Devi, R. Kaur, B. Singh, A. K. Paul and S. Tyagi, J. Nanosci. Nanotechnol., 2018, 18, 6838-6849.

19 S. Devi, B. Singh, A. Paul and S. Tyagi, Anal. Methods, 2016, 8, 4398-4405.

20 S. Devi, R. Kaur, A. K. Paul and S. Tyagi, Colloid Polym. Sci., 2018, 1-4.

21 Q. Sun, S. Fang, Y. Fang, Z. Qian and H. Feng, Talanta, 2017, 167, 513-519.

22 H. Ao, H. Feng, X. Huang, M. Zhao and Z. Qian, J. Mater. Chem. C, 2017, 5, 2826-2832.

23 S. Hughes, S. S. Dasary, S. Begum, N. Williams and H. Yu, Sens. Bio-Sens. Res., 2015, 5, 37-41.

24 M. Wanko, J. Houmøller, K. Støchkel, M.-B. S. Kirketerp, M. A. Petersen, M. B. Nielsen, S. B. Nielsen and A. Rubio, Phys. Chem. Chem. Phys., 2012, 14, 12905-12911.

25 A. Bailey and S. G. Murray, Propellants, Explos., Pyrotech., 1989, 21-47.

26 H. Peng and J. Travas-Sejdic, Chem. Mater., 2009, 21, 5563. 27 Y. Wang and A. Hu, J. Mater. Chem. C, 2014, 2, 6921-6939.

28 Y. Dong, R. Wang, H. Li, J. Shao, Y. Chi, X. Lin and G. Chen, Carbon, 2012, 50, 2810-2815.

29 L. Wang and H. S. Zhou, Anal. Chem., 2014, 86, 8902-8905. 30 R. Zhang and W. Chen, Biosens. Bioelectron., 2014, 55, 83.

31 Y. Jiang, Q. Han, C. Jin, J. Zhang and B. Wang, Mater. Lett., 2015, 141, 366-368.

32 R. Liu, H. Li, W. Kong, J. Liu, Y. Liu, C. Tong, X. Zhang and Z. Kang, Mater. Res. Bull., 2013, 48, 2529-2534.

33 Y. Zhuo, H. Miao, D. Zhong, S. Zhu and X. Yang, Mater. Lett., 2015, 139, 197-200.

34 M. Fu, F. Ehrat, Y. Wang, K. Z. Milowska, C. Reckmeier, A. L. Rogach, J. K. Stolarczyk, A. S. Urban and J. Feldmann, Nano Lett., 2015, 15, 6030-6035.

35 Y. Zhang, Y. Wang, X. Feng, F. Zhang, Y. Yang and X. Liu, Appl. Surf. Sci., 2016, 387, 1236-1246.

36 S. Zhu, Y. Song, X. Zhao, J. Shao, J. Zhang and B. Yang, Nano Res., 2015, 8, 355-381. 
37 L. Chunduri, A. Kurdekar, S. Patnaik, B. V. Dev, T. M. Rattan and V. Kamisetti, Mater. Focus, 2016, 5, 55-61.

38 S. R. M. Santiago, Y. A. Wong, T.-N. Lin, C.-H. Chang, C.-T. Yuan and J.-L. Shen, Opt. Lett., 2017, 42, 3642-3645.

39 Y.-P. Sun, B. Zhou, Y. Lin, W. Wang, K. A. S. Fernando, P. Pathak, M. J. Meziani, B. A. Harruff, X. Wang, H. F. Wang, P. G. Luo, H. Yang, M. E. Kose, B. L. Chen, L. M. Veca and S.-Y. Xie, J. Am. Chem. Soc., 2006, 128, 7756-7757.

40 J. G. Zhou, C. Booker, R. Y. Li, X. T. Zhou, T.-K. Sham, X. L. Sun and Z. F. Ding, J. Am. Chem. Soc., 2007, 129, 744745.

41 D. Y. Pan, J. C. Zhang, Z. Li and M. H. Wu, Adv. Mater., 2010, 22, 734-738.

42 A. B. Bourlinos, A. Stassinpoulos, D. Anglos, R. Zboril, M. Karakassides and E. P. Giannelis, Small, 2008, 4, 455-458.
43 Z. S. Qian, J. Zhou, J. J. Ma, X. Y. Shan, C. C. Chen, J. R. Chen and H. Feng, J. Mater. Chem. C, 2013, 1, 307-314.

44 Z. Luo, S. Lim, Z. Tian, J. Shang, L. Lai, B. MacDonald, C. Fu, Z. Shen, T. Yu and J. Lin, J. Mater. Chem., 2011, 21, 8038.

45 E. R. Goldman, I. L. Medintz, J. L. Whitley, A. Hayhurst, A. R. Clapp, H. T. Uyeda, J. R. Deschamps, M. E. Lassman and H. Mattoussi, J. Am. Chem. Soc., 2005, 127, 6744-6751.

$46 \mathrm{~S} . \mathrm{Xu}, \mathrm{H}$. Lu, J. Li, X. Song, A. Wang, L. Chen and S. Han, ACS Appl. Mater. Interfaces, 2013, 5, 8146-8154.

47 L. Fan, Y. Hu, X. Wang, L. Zhang, F. Li, D. Han, Z. Li, Q. Zhang, Z. Wang and L. Niu, Talanta, 2012, 101, 192-197. 48 L. Feng, C. Tong, Y. He, B. Liu, C. Wang, J. Sha and C. Lü, J. Lumin., 2014, 146, 502-507.

49 S. Tao and G. Li, Colloid Polym. Sci., 2007, 285, 721-728.

50 Y. Xia, L. Song and C. Zhu, Anal. Chem., 2011, 83, 1401-1407. 